\title{
Use of cement kiln dust to remove copper from simulated wastewater using the Response surface methodology
}

\author{
Hanan A. Ibraheem $^{a *}$, Husham M.Al.Tameemi ${ }^{a}$ \\ ${ }^{a}$ University of Al-Qadisiyah, Qadisiyah, Iraq
}

\author{
ARTICLE INFO \\ Article history: \\ Received 13 June 2020 \\ Received in revised form 20 August 2020 \\ Accepted 30 August 2020 \\ Keywords: \\ CKD \\ Wastewater \\ Copper removal \\ Response surface methodology
}

\begin{abstract}
A B S T R AC T
Copper removal from simulated wastewater was achieved using Cement Kiln Dust (CKD) as adsorbent. The effects of contact time, $\mathrm{pH}$, initial copper ion concentration, rotational speed, and Cement Kiln Dust (CKD) amount were studied. The best operating conditions were determined by applying a Response Surface Methodology (RSM). The results showed that the copper concentration has the main effect on the efficiency of copper removal followed by time, shaking rate, dosage of cement kiln dust, and $\mathrm{pH}$. The best operating conditions were found to have a $\mathrm{pH}$ value of 8 , contact time 90 minutes, shaking rate of $300 \mathrm{rpm}$, copper ion concentration $20 \mathrm{ppm}$, and a quantity of CKD equivalent to $35 \mathrm{~g} / 1$. Based on this optimum condition, $99 \%$ of the efficiency of copper removal was achieved.
\end{abstract}

C2020 University of Al-Qadisiyah. All rights reserved.

\section{Introduction}

Due to the increase in human activities represented by factories, mining operations, and household needs, there is a growing demand for water usage and, at the same time, there has been an increase in the output of wastewater in general, especially industrial wastewater resulting from the production processes. This water is charged with many pollutants, in particular pollutants represented by inorganic materials with heavy metals such as copper. Copper is considered as the most dangerous pollutant in the water among other inorganic pollutants because it may cause many diseases such as cancer as can be accumulated inside the bodies of living organisms [1, 2]. Although copper is important to the body of the living organism, but the increase of its concentration in water above $3.0 \mathrm{mg} / 1$ causes liver cirrhosis, brain necrosis, and kidney damage [3, 4]; therefore, scientists resorted to finding ways to get rid of these minerals and address the problem of water pollution Bailey et al. [5]. Several methods have been used to remove copper, including electrodeposition, adsorption, reverse osmosis, etc. [5-9],

* Corresponding author.

E-mail address: hanankarkoosh@gmail.com (Hanan A.Ibraheem) but these methods were expensive, not highly efficient; therefore, the researchers continued their attempts to find economical and highly efficient methods by using the materials available in the environment.

Recently, adsorption was used by many authors, and an inexpensive material such as Cement Kiln Dust (CKD) as a sorbent. CKD is a byproduct of cement manufacturing operations which has a basic property and its particles size very small Mustafa et al. [10]. Its presence causes environmental pollution because it affects a person's respiratory system. It is used in many processes, including soil stabilization Rahman et al. [11], the production of fertilizers and building materials, and as an absorbent [1215].

The present research aims to investigate the capacity of the CKD generated locally as a pipette to extract copper from wastewater. To obtain optimum operating conditions, for the response surface methodology, has been adopted. 


\begin{tabular}{|llll|}
\hline \multicolumn{2}{|l}{ Nomenclature } & & \\
$a i$ & The first-class(linear) major effect & $\mathrm{S}$ & Standard error of mean \\
aii & Second-class major effect & $\mathrm{K}$ & Number of process variables \\
aij & The interaction effect & $\mathrm{Y}$ & Represents the dependent variable (RE) \\
$a o$ & The code of intercept & $\mathrm{SE}$ & Standard Error of the Regression \\
$B B D$ & Box-Behnken Design & $\mathrm{N}$ & Number of runs \\
$c k d$ & cement kiln dust & $\mathrm{cp}$ & Reiterated number of the central point \\
$C u$ & Copper & $\mathrm{CI}$ & Confidence interval \\
$t$ & time, s & ANOVA & Analysis of variance \\
$X 1$ & Concentration of copper, ppm & PI & Prediction interval \\
$x 1$ & coded value of copper Concentration & DOF & Degree of freedom \\
$X 2$ & Concentration of CKD , g/l & Adj. SS & Adjusted sum of the square \\
$x 2$ & coded value of CKD Concentration & D & Desirability function \\
$X 3$ & Shaking rate, rpm & Adj. MS & Adjusted mean of the square \\
$X 4$ & pH & Seq. SS & Sum of square \\
$x 3$ & coded value of shaking rate & adj. R2 & Adjusted coefficient of multiple correlation \\
$x 4$ & coded value of pH & pred. R2 & Predicted multiple correlation coefficient \\
$X 5$ & Contact time, min & Cr. \% & Percentage contribution for each parameter \\
$x 5$ & coded value of contact time & RE & Removal Efficiency (\%) \\
\hline
\end{tabular}

\section{MATERIALS AND METHODS}

\subsection{CKD characterization}

A quantity of $2 \mathrm{~kg}$ of CKD was taken from Al-Duh Cement Factory located south of Al-Muthanna Governorate. The material was dried in a laboratory oven at a temperature of $100{ }^{\circ} \mathrm{C}$. XRD and EDX examination were performed in the laboratories of the Ministry of Science and Technology / Materials Research Department in Baghdad using an analyzer Spectrometer (A Philips X-ray diffraction (equipment model PW/1710 with Monochromatic 2009)).

\subsection{Preparation of copper solution}

Copper sulfate $\left(\mathrm{CuSO}_{4} .5 \mathrm{H}_{2} \mathrm{O}\right)$ was used to prepare the copper ions solution at concentrations $(20,60$, and $100 \mathrm{ppm})$ by dissolving the appropriate amount in $400 \mathrm{~mL}$ of distilled water. Then adjust the $\mathrm{pH}$ of the prepared solution using $0.1 \mathrm{M} \mathrm{NaOH}$ and/or $0.1 \mathrm{M} \mathrm{HCl}$ to $(2,5$, and 8$) \mathrm{pH}$. After that, the required amount of CKD was added at concentrations of (5, 20 , and 35$) \mathrm{g} / \mathrm{L}$ to the copper solution and then shake the solution at a rate of Different rotations (100, 200, and $300 \mathrm{rpm})$ and different times (30, 60 and 90 minutes). After the adsorption process was completed, the solution was filtered and a sample $(5 \mathrm{ml})$ was taken to determine the concentration of copper residue with the atomic absorption spectrometer (japan, 2002).

All experiments were conducted at room temperature, hence average values were considered for data analysis.

The copper removal efficiency ( $\mathrm{R} \%$ ) by using $\mathrm{CKD}$ was calculated according to the following formula (Eq. 1)

$R \%=\left(C_{0^{-}} C\right) / C_{0} * 100$

Where $\mathrm{C}_{0}$ is the initial concentration of the copper solution and $\mathrm{C}$ is that the final concentration of the copper solution.

\subsection{Design of experiments}

The relationship between a process response and its variables will be determined by applying a group of mathematical and statistical techniques adopted by RSM Bezerra et al. [16]. During this study, the 3-level 5-factor Box-Behnken experimental designs are implemented to verification and check the variables that influenced the removal of copper from simulated wastewater. Initial copper ion concentration (X1) CKD dosage (g/l) (X2), shaking rate (rpm) (X3), $\mathrm{pH}$ value $(\mathrm{X} 4)$, and contact time ( $\mathrm{min})(\mathrm{X} 5)$ were taken as process variables, while the efficiency of copper removal was taken as a response. The scales of process variables were coded as -1 (low level), 0 (middle or central point), and 1 (high level) Evans et al. [17]. Table 1 illustrates the method variables with their chosen levels. Box-Behnken improves designs to urge the acceptable quadratic model with the desired statistical properties by using only an element of the runs needed for a 3level factorial Huiping et al. [18]. The number of runs $(\mathrm{N})$ needed for performing of Box-Behnken design will be determined by the subsequent equation [2]:

$$
N=2 k(k-1)+c p
$$

Where $\mathrm{k}$ is the number of process variables and $\mathrm{cp}$ is the reiterated number of the central point.

In this work, forty six runs were conducted to evaluating the effects of the process variables on the copper removal efficiency. Table 2 illustrates the Box-Behnken Design (BBD) proposed for the present research.

A second order polynomial model can be adopted based on BBD were fitting the interaction terms with the experimental data can be described by the following equation [3]:

$Y=a_{0}+\sum a_{i} x_{i}+\sum a_{i i} x_{i}^{2}+\sum a_{i j} x_{i} x_{j}$

Where $\mathrm{Y}$ represents the variable (RE), $\mathrm{i}$ and $\mathrm{j}$ are the index numbers for patterns, $a_{0}$ is intercept term, $x_{1}, x_{2} \ldots x_{k}$ are the method variables (independent variables) in coded form. $a_{i i s}$ the first-order (linear) main effect, $a_{i i}$ second-order main effect, and $a_{i j}$ is that the interaction effect.

Analysis of variance was performed then the parametric statistic $\left(\mathrm{R}^{2}\right)$ was estimated to verify the goodness of model fit. 
Table 1. Process variables with their level for Copper removal

\begin{tabular}{llll}
\hline Process parameters & \multicolumn{3}{l}{ range in Box-Behnken design } \\
\hline Coded levels & Low(-1) & Middle $(0)$ & High $(+1)$ \\
X1- Initial conc. $(\mathrm{ppm})$ & 20 & 60 & 100 \\
X2- CKD dosage $(\mathrm{g} / \mathrm{l})$ & 5 & 20 & 35 \\
X3- Shaking rate(rpm) & 100 & 200 & 300 \\
X4-pH value & 2 & 5 & 8 \\
X5-Contact time(min) & 30 & 60 & 90 \\
\hline
\end{tabular}

Table 2 .Box- Behnken experimental design

\begin{tabular}{|c|c|c|c|c|c|c|c|c|c|c|c|}
\hline Run & $\frac{n}{\frac{n}{0}}$ & X1 & $\mathbf{X} 2$ & $\mathbf{X 3}$ & X4 & X5 & 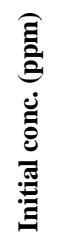 & 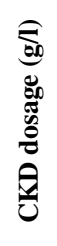 & 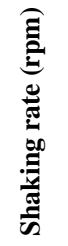 & 플 & 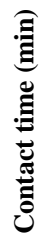 \\
\hline 1 & 1 & $1-$ & 1 & 0 & 0 & 0 & 20 & 35 & 200 & 5 & 60 \\
\hline 2 & 1 & 0 & 1 & 1- & 0 & & 60 & 35 & 100 & 5 & 60 \\
\hline 3 & 1 & 0 & 1 & 0 & 0 & 1 & 60 & 35 & 200 & 5 & 90 \\
\hline 4 & 1 & 0 & 1 & 0 & $1-$ & 0 & 60 & 35 & 200 & 2 & 60 \\
\hline 5 & 1 & 0 & 0 & 1 & 0 & 1- & 60 & 20 & 300 & 5 & 30 \\
\hline 6 & 1 & 1 & 0 & 1 & 0 & 0 & 100 & 20 & 300 & 5 & 60 \\
\hline 7 & 1 & 0 & 0 & 0 & 1 & $1-$ & 60 & 20 & 200 & 8 & 30 \\
\hline 8 & 1 & 0 & 0 & 1 & $1-$ & 0 & 60 & 20 & 300 & 2 & 0 \\
\hline 9 & 1 & 0 & 0 & 0 & 0 & 0 & 60 & 20 & 200 & 5 & 60 \\
\hline 10 & 1 & 0 & $1-$ & 0 & 1- & ( & 60 & 5 & 200 & 2 & 60 \\
\hline 11 & 1 & 0 & 0 & 0 & $1-$ & 1 & 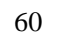 & 20 & 200 & 2 & 90 \\
\hline 12 & 1 & 1- & 0 & $1-$ & 0 & 0 & 20 & 20 & 100 & 5 & 60 \\
\hline 13 & 1 & 0 & 0 & 1 & 1 & 0 & 60 & 20 & 300 & 8 & 60 \\
\hline 14 & 1 & 0 & 0 & 1 & 0 & 1 & 60 & 20 & 300 & 5 & 90 \\
\hline 15 & 1 & $1-$ & 0 & 0 & $1-$ & 0 & 20 & 20 & 200 & 2 & 60 \\
\hline 16 & 1 & 0 & 0 & 0 & 1- & $1-$ & & 0 & 200 & 2 & 30 \\
\hline 17 & 1 & 0 & 0 & 1- & . & $1-$ & 60 & 20 & 100 & 5 & 30 \\
\hline 18 & 1 & 1- & 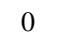 & 0 & 1 & 0 & 20 & 20 & 200 & 8 & 50 \\
\hline 19 & 1 & 1 & 0 & 0 & 0 & $1-$ & 100 & 20 & 200 & 5 & 30 \\
\hline 20 & 1 & 0 & 1 & 0 & 0 & 1- & 60 & 5 & 200 & 5 & 30 \\
\hline 21 & 1 & 0 & 0 & 0 & 0 & 0 & 60 & 20 & 200 & 5 & 60 \\
\hline 22 & 1 & 0 & $1-$ & 1 & 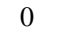 & 0 & 60 & 5 & 300 & 5 & 60 \\
\hline 23 & 1 & 1- & 0 & 1 & 0 & 0 & 20 & 20 & 300 & 5 & 60 \\
\hline 24 & 1 & 0 & 0 & 0 & 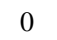 & 0 & 6 & 20 & 200 & 5 & 60 \\
\hline 25 & 1 & 0 & 0 & 0 & 0 & 0 & 6 & 20 & 200 & 5 & 60 \\
\hline 26 & 1 & 0 & 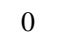 & 1- & 1 & 0 & 60 & 20 & 100 & 8 & 60 \\
\hline 27 & 1 & 0 & 1 & 0 & 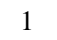 & 0 & 60 & 35 & 200 & 8 & 60 \\
\hline 28 & 1 & 0 & 1 & 1 & 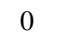 & 0 & 60 & 35 & 300 & 5 & 60 \\
\hline 29 & 1 & 1 & 0 & 0 & 1 & 0 & 100 & 20 & 200 & 8 & 60 \\
\hline 30 & 1 & 1- & 0 & 0 & 0 & 1 & 20 & 20 & 200 & 5 & 90 \\
\hline 31 & 1 & 1- & 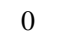 & 0 & 0 & $1-$ & 20 & 20 & 200 & 5 & 30 \\
\hline 32 & 1 & 1 & 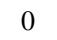 & 0 & 1- & 0 & 100 & 20 & 200 & 2 & 60 \\
\hline 33 & 1 & 0 & 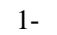 & 0 & 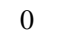 & $1-$ & 60 & 5 & 20 & 5 & 30 \\
\hline 34 & 1 & 1 & 0 & 1- & 0 & 0 & 100 & 20 & 100 & 5 & 60 \\
\hline 35 & 1 & 0 & 1- & 0 & 0 & 1 & 60 & 5 & 200 & 5 & 90 \\
\hline 36 & 1 & $1-$ & 1- & 0 & 0 & 0 & 20 & 5 & 200 & 5 & 60 \\
\hline 37 & 1 & 0 & $1-$ & 0 & 1 & 0 & 60 & 5 & 200 & 8 & 60 \\
\hline 38 & 1 & 0 & 0 & 1- & 1- & 0 & 60 & 20 & 100 & 2 & 60 \\
\hline 39 & 1 & 0 & 0 & 0 & 0 & 0 & 60 & 20 & 200 & 5 & 60 \\
\hline 40 & 1 & 1 & 1 & 0 & 0 & 0 & 100 & 35 & 200 & 5 & 60 \\
\hline 41 & 1 & 0 & 0 & 1- & 0 & 1 & 60 & 20 & 100 & 5 & 90 \\
\hline 42 & 1 & 1 & 0 & 0 & 0 & 1 & 100 & 20 & 200 & 5 & 90 \\
\hline 43 & 1 & 0 & 1- & 1- & 0 & 0 & 60 & 5 & 100 & 5 & 60 \\
\hline 44 & 1 & 0 & 0 & 0 & 0 & 0 & 60 & 20 & 200 & 5 & 60 \\
\hline 45 & 1 & 1 & 1- & 0 & 0 & 0 & 100 & 5 & 200 & 5 & 60 \\
\hline 46 & 1 & 0 & 0 & 0 & 1 & 1 & 60 & 20 & 200 & 8 & 90 \\
\hline
\end{tabular}

\section{Results and discussion}

\subsection{CKD properties}

XRD analysis of CKD was carried out in the target was copper $(\lambda=$ $1.5406 \mathrm{~A}^{\circ}$ ) at $40 \mathrm{kV}, 30 \mathrm{~mA}$, and the scanning speed was $5^{\circ} \mathrm{min}-1$. The reflection peaks between $2 \theta=5^{\circ}$ and $80^{\circ}$, corresponding spacing $\left(\mathrm{d}, \mathrm{A}^{\circ}\right)$, present time ( $0.6 \mathrm{~s})$ and relative intensities (I/Io) were obtained Table 3.

Table 3. The chemical composition of CKD

\begin{tabular}{lllllllll}
\hline Components $\mathrm{CaO}$ & $\mathrm{Sio} 2$ & $\mathrm{So} 3$ & $\mathrm{~K} 2 \mathrm{O}$ & $\mathrm{Al2O} 3$ & $\mathrm{Fe} 2 \mathrm{O} 3$ & $\mathrm{MgO}$ & L.O.I \\
\hline Average \% & 47.81 & 17.3 & 11.98 & 4.9 & 3.7 & 2.6 & 2.5 & 9.21 \\
\hline
\end{tabular}

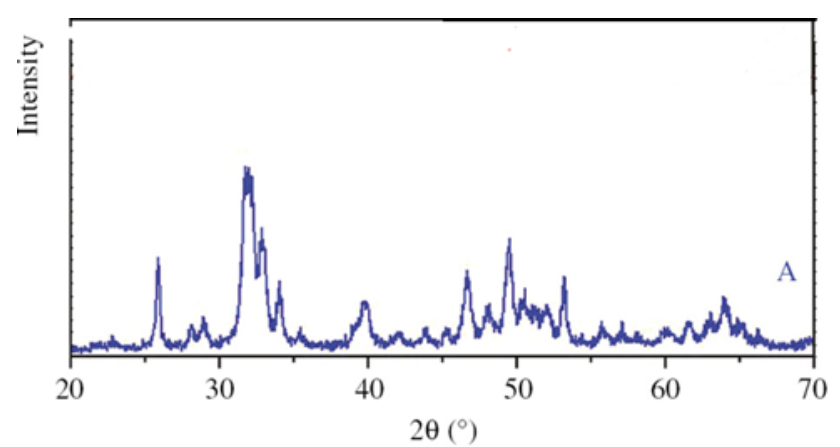

Figure 1. XRD for CKD

\subsection{Statistical analysis}

Statistical approaches like RSM are employed to maximize the assembly of a special substance by optimization of operational factors. In contrast to traditional methods, the interaction among process variables is determined by statistical techniques.46 experiments were performed with different variables of the process in different groups to determine their effect on the removal ratios and the knowledge of the optimization between them.

Table 4 shows the removal values for each experiment. The current and expected efficiencies are included in this table. It is interesting to note that the copper removal efficiency was changed from 35.59 to $100 \%$, upon approval of the experimental design.

The Minitab-17 program is used to analyze the results of the copper removal efficiency as a pilot relationship between the copper removal efficiency and process variables were formulated through the quadratic model of the Removal Efficiency copper (RE) in terms of encoded units for process variables:

$\mathrm{RE} \%=148.0-1.599 \mathrm{X} 1-0.515 \mathrm{X} 2-0.091 \mathrm{X} 3+2.17 \mathrm{X} 4-1.173 \mathrm{X} 5+$ $0.00623 \mathrm{X} 12+0.00434 \mathrm{X} 22+0.000259 \mathrm{X} 32-0.080 \mathrm{X} 42+0.00986$ $\mathrm{X} 52+0.00798 \mathrm{X} 1 \mathrm{X} 2+0.000096 \mathrm{X} 1 \mathrm{X} 3+0.0041 \mathrm{X} 1 \mathrm{X} 4+0.00123 \mathrm{X} 1$ $\mathrm{X} 5-0.00060 \mathrm{X} 2 \mathrm{X} 3+0.0816 \mathrm{X} 2 \mathrm{X} 4+0.00343 \mathrm{X} 2 \mathrm{X} 5+0.00162 \mathrm{X} 3 \mathrm{X} 4+$ $0.000765 \times 3 \times 5-0.0162 \times 4 \times 5$

(4)

Equation (4) shows the effect of removal efficiency with the variables (squared and linear). Increasing efficiency values increase with increasing values of positive coefficients depending on the laboratory scale, whereas. 
Table 4. The experimental results of "Box-Behnken design" for the copper removal

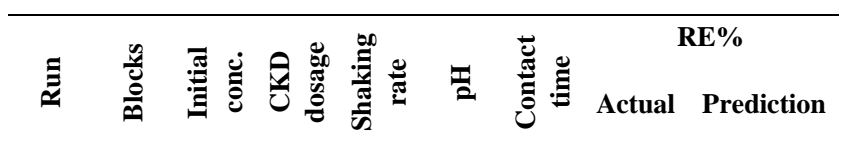

\begin{tabular}{ccccccccc}
\hline 1 & 1 & 20 & 35 & 200 & 5 & 60 & 97.03 & 91.90 \\
2 & 1 & 60 & 35 & 100 & 5 & 60 & 58.76 & 61.07 \\
3 & 1 & 60 & 35 & 200 & 5 & 90 & 79.73 & 80.74 \\
4 & 1 & 60 & 35 & 200 & 2 & 60 & 53.46 & 58.03 \\
5 & 1 & 60 & 20 & 300 & 5 & 30 & 68.21 & 66.30 \\
6 & 1 & 100 & 20 & 300 & 5 & 60 & 54.64 & 53.67 \\
7 & 1 & 60 & 20 & 200 & 8 & 30 & 69.49 & 64.74 \\
8 & 1 & 60 & 20 & 300 & 2 & 60 & 57.29 & 61.26 \\
9 & 1 & 60 & 20 & 200 & 5 & 60 & 57.83 & 57.88 \\
10 & 1 & 60 & 5 & 200 & 2 & 60 & 52.37 & 50.24 \\
11 & 1 & 60 & 20 & 200 & 2 & 90 & 74.31 & 70.23 \\
12 & 1 & 20 & 20 & 100 & 5 & 60 & 91.2 & 87.96 \\
13 & 1 & 60 & 20 & 300 & 8 & 60 & 65.83 & 70.22 \\
14 & 1 & 60 & 20 & 300 & 5 & 90 & 87.76 & 84.37 \\
15 & 1 & 20 & 20 & 200 & 2 & 60 & 89.99 & 86.76 \\
16 & 1 & 60 & 20 & 200 & 2 & 30 & 55.69 & 53.83 \\
17 & 1 & 60 & 20 & 100 & 5 & 30 & 60.26 & 58.89 \\
18 & 1 & 20 & 20 & 200 & 8 & 60 & 95.15 & 93.77 \\
19 & 1 & 100 & 20 & 200 & 5 & 30 & 39.31 & 45.36 \\
20 & 1 & 60 & 35 & 200 & 5 & 30 & 63.5 & 64.17 \\
21 & 1 & 60 & 20 & 200 & 5 & 60 & 57.98 & 57.87 \\
22 & 1 & 60 & 5 & 300 & 5 & 60 & 65.98 & 63.61 \\
23 & 1 & 20 & 20 & 300 & 5 & 60 & 100 & 99.19 \\
24 & 1 & 60 & 20 & 200 & 5 & 60 & 57.86 & 57.87 \\
25 & 1 & 60 & 20 & 200 & 5 & 60 & 57.88 & 57.87 \\
26 & 1 & 60 & 20 & 100 & 8 & 60 & 52.19 & 57.24 \\
27 & 1 & 60 & 35 & 200 & 8 & 60 & 62.49 & 67.69 \\
28 & 1 & 60 & 35 & 300 & 5 & 60 & 70.18 & 71.26 \\
29 & 1 & 100 & 20 & 200 & 8 & 60 & 48.51 & 48.46 \\
30 & 1 & 20 & 20 & 200 & 5 & 90 & 99.13 & 105.13 \\
31 & 1 & 20 & 20 & 200 & 5 & 30 & 91.97 & 94.60 \\
32 & 1 & 100 & 20 & 200 & 2 & 60 & 41.38 & 39.49 \\
33 & 1 & 60 & 5 & 200 & 5 & 30 & 57.27 & 57.80 \\
34 & 1 & 100 & 20 & 100 & 5 & 60 & 44.3 & 40.98 \\
35 & 1 & 60 & 5 & 200 & 5 & 90 & 67.33 & 68.19 \\
36 & 1 & 20 & 5 & 200 & 5 & 60 & 86.86 & 92.02 \\
37 & 1 & 60 & 5 & 200 & 8 & 60 & 58.05 & 56.55 \\
38 & 1 & 60 & 20 & 100 & 2 & 60 & 45.59 & 50.23 \\
39 & 1 & 60 & 20 & 200 & 5 & 60 & 57.85 & 57.87 \\
40 & 1 & 100 & 35 & 200 & 5 & 60 & 64.92 & 55.20 \\
41 & 1 & 60 & 20 & 100 & 5 & 90 & 70.63 & 67.78 \\
42 & 1 & 100 & 20 & 200 & 5 & 90 & 52.37 & 61.79 \\
43 & 1 & 60 & 5 & 100 & 5 & 60 & 50.94 & 49.80 \\
44 & 1 & 60 & 20 & 200 & 5 & 60 & 57.85 & 57.87 \\
\hline & 1 & 100 & 5 & 200 & 5 & 60 & 35.59 & 36.16 \\
& 1 & 60 & 20 & 200 & 8 & 90 & 82.27 & 75.30 \\
\hline & & & & & & & & \\
3 & 1 &
\end{tabular}

Removal efficiency decreases by increasing coefficients with negative values and it was found that the positive effect is for the amount of $\mathrm{CKD}$ and $\mathrm{pH}$. The expected values of removal efficiency are listed in Table 5 according to the estimated values from equation (4).
Table 5 Analysis of variance for copper removal

\begin{tabular}{|c|c|c|c|c|c|c|c|}
\hline 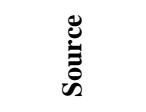 & $\frac{5}{0}$ & 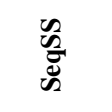 & ن̃ & : & $\sum_{i}^{\infty}$ & 窇 & 窇 \\
\hline Model & 20 & 12134.4 & $95.10 \%$ & 12134.4 & 606.72 & 24.29 & 0.000 \\
\hline Linear & 5 & 10486.7 & $82.19 \%$ & 10486.7 & 2097.34 & 83.95 & 0.000 \\
\hline $\mathrm{X} 1$ & 1 & 8570.6 & $67.17 \%$ & 8570.6 & 8570.59 & 343.06 & 0.000 \\
\hline $\mathrm{X} 2$ & 1 & 358.0 & $2.81 \%$ & 358.0 & 357.97 & 14.33 & 0.001 \\
\hline $\mathrm{X} 3$ & 1 & 576.2 & $4.52 \%$ & 576.2 & 576.24 & 23.07 & 0.000 \\
\hline $\mathrm{X} 4$ & 1 & 255.2 & $2.00 \%$ & 255.2 & 255.20 & 10.21 & 0.004 \\
\hline $\mathrm{X} 5$ & 1 & 726.7 & $5.70 \%$ & 726.7 & 726.71 & 29.09 & 0.000 \\
\hline Square & 5 & 1499.6 & $11.75 \%$ & 1499.6 & 299.91 & 12.00 & 0.000 \\
\hline $\mathrm{X} 1^{2}$ & 1 & 703.5 & $5.51 \%$ & 867.2 & 867.17 & 34.71 & 0.000 \\
\hline $\mathrm{X} 2^{2}$ & 1 & 8.6 & $0.07 \%$ & 8.3 & 8.34 & 0.33 & 0.569 \\
\hline$X 3^{2}$ & 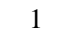 & 7.0 & $0.05 \%$ & 58.3 & 58.35 & 2.34 & 0.139 \\
\hline$X 4^{2}$ & 1 & 93.1 & $0.73 \%$ & 687.4 & 4.56 & 0.18 & 0.673 \\
\hline$X 5^{2}$ & 1 & 687.4 & $5.39 \%$ & 4.6 & 687.38 & 27.51 & 0.000 \\
\hline $\begin{array}{c}\text { 2-Way } \\
\text { Interaction }\end{array}$ & 10 & 148.2 & $1.16 \%$ & 148.2 & 14.82 & 0.59 & 0.804 \\
\hline $\mathrm{X} 1 * \mathrm{X} 2$ & 1 & 91.8 & $0.72 \%$ & 91.8 & 91.78 & 3.67 & 0.067 \\
\hline $\mathrm{X} 1 * \mathrm{X} 3$ & 1 & 0.6 & $0.00 \%$ & 0.6 & 0.5 & 0.02 & 0.879 \\
\hline $\mathrm{X} 1 * \mathrm{X} 4$ & 1 & 1.0 & $0.01 \%$ & 1.0 & 0.97 & 0.04 & 0.845 \\
\hline $\mathrm{X} 1 * \mathrm{X} 5$ & 1 & 8.7 & $0.07 \%$ & 8.7 & 8.70 & 0.35 & 0.560 \\
\hline $\mathrm{X} 2 * \mathrm{X} 3$ & 1 & 3.3 & $0.03 \%$ & 3.3 & 3.28 & 0.13 & 0.720 \\
\hline $\mathrm{X} 2 * \mathrm{X} 4$ & 1 & 2.8 & $0.02 \%$ & 2.8 & 2.81 & 0.11 & 0.740 \\
\hline $\mathrm{X} 2 * \mathrm{X} 5$ & 1 & 9.5 & $0.07 \%$ & 9.5 & 9.52 & 0.38 & 0.543 \\
\hline $\mathrm{X} 3 * \mathrm{X} 4$ & 1 & 0.9 & $0.01 \%$ & 0.9 & 0.94 & 0.04 & 0.848 \\
\hline $\mathrm{X} 3 * \mathrm{X} 5$ & 1 & 21.1 & $0.17 \%$ & 21.1 & 21.07 & 0.84 & 0.367 \\
\hline $\mathrm{X} 4 * \mathrm{X} 5$ & 1 & 8.5 & $0.07 \%$ & 8.5 & 8.53 & 0.34 & 0.564 \\
\hline Error & 25 & 624.6 & $4.90 \%$ & 624.6 & 24.98 & & \\
\hline Lack-of-Fit & 20 & 624.6 & $4.90 \%$ & 624.6 & 31.23 & 10731.3 & 0.000 \\
\hline Pure Error & 5 & 0.0 & $0.00 \%$ & 0.0 & 0.00 & & \\
\hline \multirow[t]{2}{*}{ Total } & 45 & 12759.0 & $100 \%$ & & & & \\
\hline & s & R-sq & R-sq(adj) & PRESS & $\begin{array}{c}\text { R- } \\
\text { sq(pred) }\end{array}$ & & \\
\hline $\begin{array}{c}\text { Model } \\
\text { Summary }\end{array}$ & $\begin{array}{c}4.998 \\
31\end{array}$ & $10 \%$ & 91 & 27 & $2 \%$ & & \\
\hline
\end{tabular}

ANOVA variance analysis was used to test hypotheses about the model coefficients which could be a statistical approach splits the full variation in a very group of information into individual parts given particular sources of variation to exam hypotheses on the parameters of the model $[19,20]$

ANOVA depends on the Fisher F-test and P-test to work out the adequacy. The massive value of $F$ reveals that almost all of the variation within the response is elucidated by the regression equation. The associated $\mathrm{P}$-value is employed to judge whether $\mathrm{F}$ is large enough to point statistical significance. With a P-value of 0.00 , the model designated could be elucidated $95.10 \%$ of the variability Segurola et al. [21].

Table 5 shows ANOVA for the response surface quadratic model. This table presents the sum of the square (SeqSS), Degree of Freedom (DF), adjusted sum of squares (Adj SS), adjusted mean of square (Adj MS., The value of $\mathrm{F}$ is equal to 24.29 at $\mathrm{P}$ equal to 0.00 percentage contribution ( $\mathrm{Cr}$. $\%$ ) of each parameter, F-value, and P-value. It shows great importance for the regression model. Model fit quality was also validated by multiple correlations for the model. In this case, the value of the multiple correlation coefficients was $95.10 \%$ which indicates that this regression statistically significant, the model only explains $4.90 \%$ of all differences. Expected value Multiple correlation coefficient (former R2 $=80.42 \%$ ) which is in a reasonable agreement with the value of the adjusted multiplier Correlation coefficient $(\mathrm{R} 2=91.19 \%)$. 
ANOVA results showed that the mineral concentration contribution percentage is $67.17 \%$, which means that mineral concentration has the main effect on copper removal efficiency. And the rest of the variables have close proportions. The linear term contains the main percentage of the contribution to the model by $82.19 \%$, followed by the interaction between the input variables with a contribution of $1.16 \%$ and it was small while the square contains a contribution of $11.75 \%$. The results confirm that the heavy metal concentration (copper) is the most important factor.

\subsection{Effect of process variables on the copper removal efficiency}

Fig. (2-a, 2-b) illustrates the effect of the initial concentration of copper metal on its removal efficiency for different values of contact time (30, 60 and $90 \mathrm{~min}$.) and initial concentration of $\mathrm{Cu}$ is $(20,60,100 \mathrm{ppm})$ at $\mathrm{pH} 5$ and the shaking rate of $200 \mathrm{rpm}$ and the CKD dosage equal to 20 $\mathrm{g} / 1$.

Fig. 2- a represents response surface diagram while Fig. 2-b shows the corresponding contour diagram. It can be seen clearly from the surface plot that at a contact time of 30 minutes, a decrease in the removal efficiency occurs with an increase in the initial copper concentration. However, there was a slight change in the removal efficiency as the contact time approached 90 minutes. In addition, at a concentration of $100 \mathrm{ppm}$, the results show an increase in the efficiency of copper removal with increasing contact time. Noting that, at a concentration of $20 \mathrm{ppm}$, a significant change in the removal efficiency occurred with increasing contact time, this was proven by the study El-Awady et al. [22].

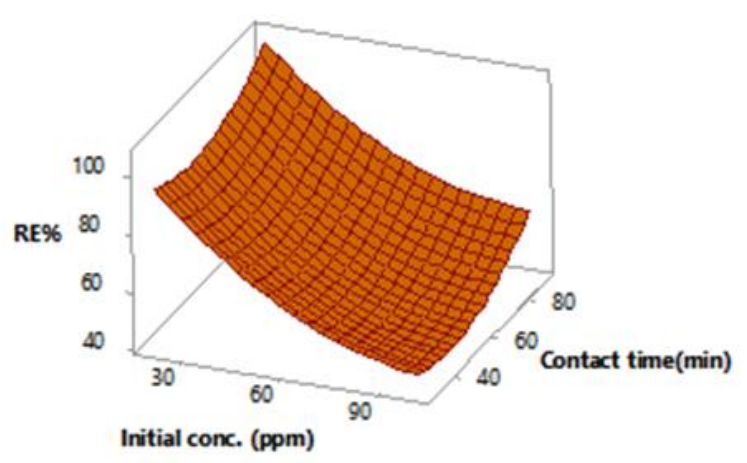

(a)
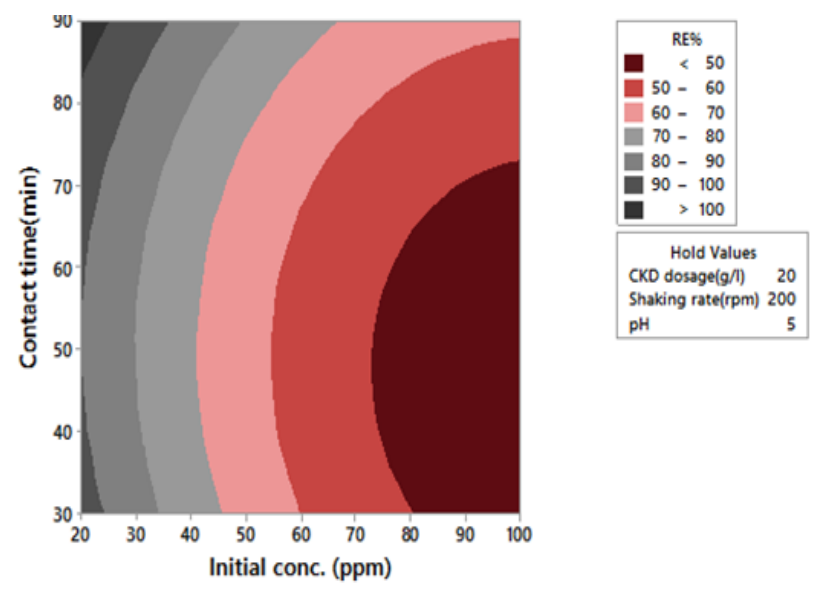

(b)

Figure 2: Response surface plot (a) and contour plot (b) showing the effect of contact time and initial concentration of copper on the copper removal efficiency
Fig.3 a and $\mathbf{3 b}$ illustrate the effect of $\mathrm{pH}$ on copper removal efficiency of different primary copper concentrations $(20,60$, and $100 \mathrm{ppm})$ at different $\mathrm{pH}$ values $(2,5$, and 8$)$ at a shaking rate of $200 \mathrm{rpm}$, a 60 -minute contact time and a CKD dosage of $20 \mathrm{~g} / 1$. The response surface plot (3a) shows that it currently has a slight impact on the copper removal efficiency as it increases slightly with increasing $\mathrm{pH}$ while decreasing efficiency decreases with increasing concentration. The corresponding contour piece (3-b) confirms that the maximum value of the copper removal efficiency lies in a very small area; It had a pH equal to 8 and a copper ion concentration of approximately $20 \mathrm{ppm}$. This was proven by the study Coruh et al.[14], [20, 21]

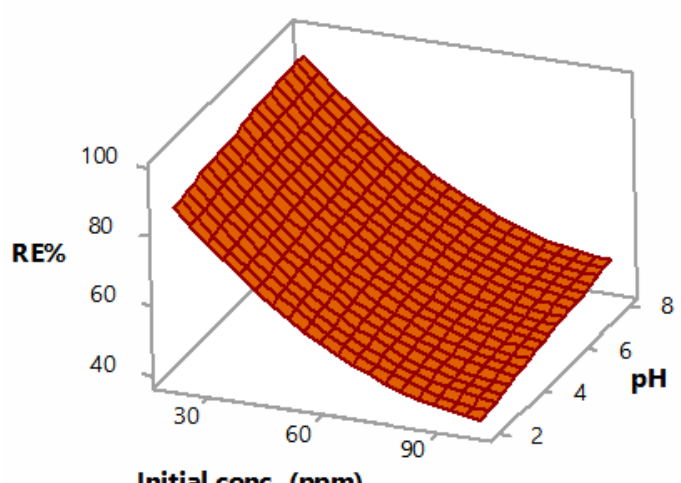

Initial conc. (ppm)

(a)
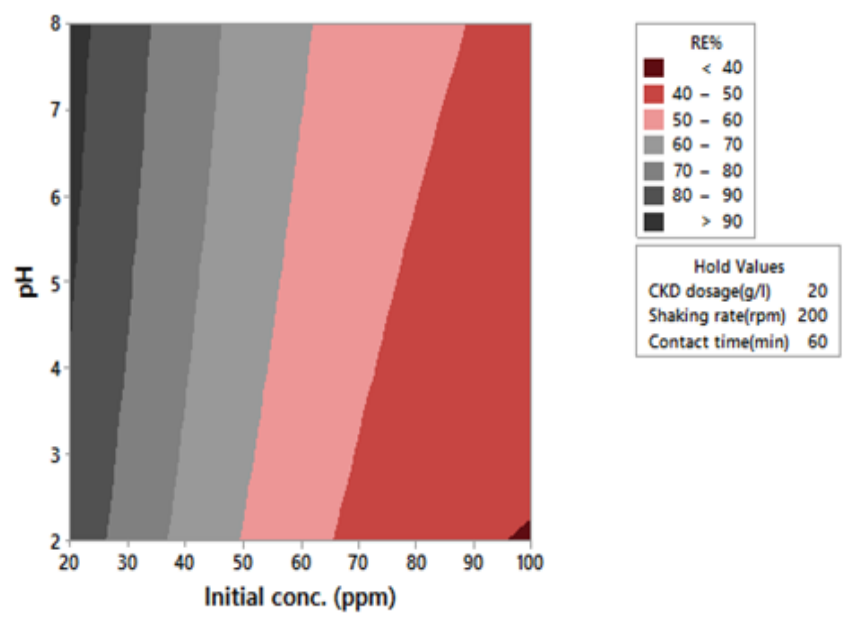

(b)

Figure 3: Response surface plot (a) and contour plot (b) showing the effect of the $\mathrm{pH}$ and initial concentration of copper on the copper removal efficiency

As for the forms (4-a, 4-b), presents the relationship of the shacking rate with the initial concentration of copper and its effect on the removal rate where the shaking rate was within $(100,200$, and $300 \mathrm{rpm})$ at an initial concentration of the copper metal (20,60 and 100) ppm. It is clear from the response surface plot (4-a) it has a significant effect on copper removal efficiency as it increases as the shaking rate increases at $300 \mathrm{rpm}$, while the removal efficiency decreased as the focus increased. The corresponding contour piece (4-b) confirms that the maximum value of the copper removal efficiency lies in a small area where the shaking rate is equal to $300 \mathrm{rpm}$ and the copper ion concentration is around $20 \mathrm{ppm}$. 


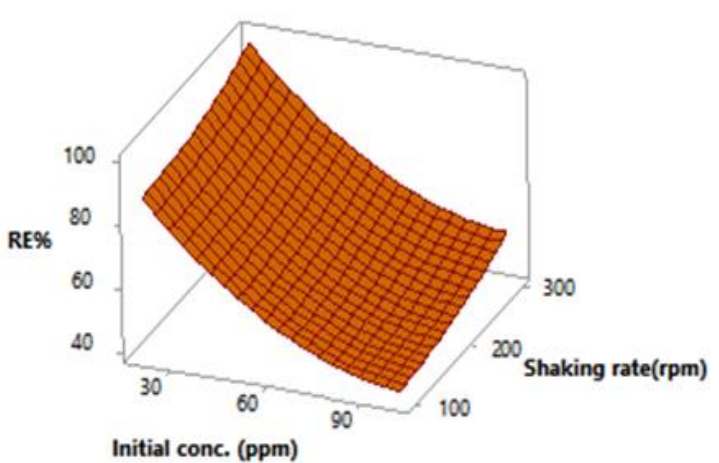

(a)

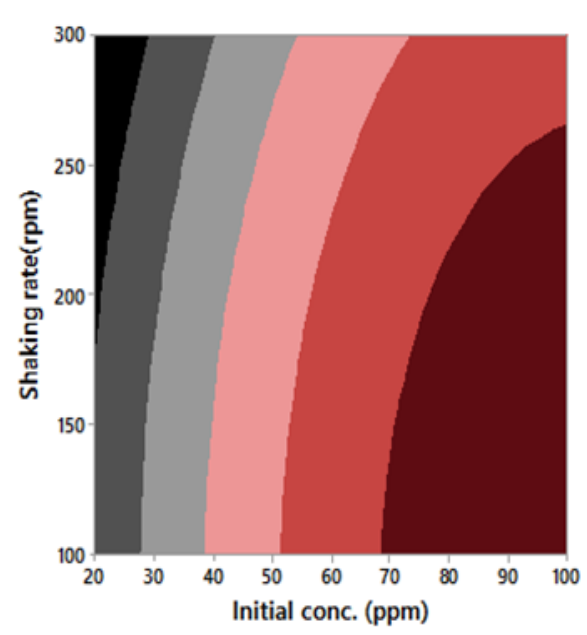

(b)

Figure 4: Response surface plot (a) and contour plot (b) showing the effect of shaking rate and initial concentration of copper on the copper removal efficiency

Fig. (5-a, 5-b) shows the effect of the CKD dosage with the initial concentration of copper and its effect on the removal rate Since the dosage of the to CKD was within $(5,20$, and 35) $\mathrm{g} / 1$ at an initial concentration of copper metal (20,60 and 100) (ppm) The response surface plot (5-a) illustrates that it currently has a significant effect on copper removal efficiency as it increases with increasing dosage of CKD at $35 \mathrm{~g} / 1$.

While the removal efficiency decreased as the focus increased. The corresponding contour piece (5-b) confirms that the maximum value of copper removal efficiency lies in a small area where the CKD dosages about $35 \mathrm{~g} / 1$ and the copper ion concentration is about $20 \mathrm{ppm}$.

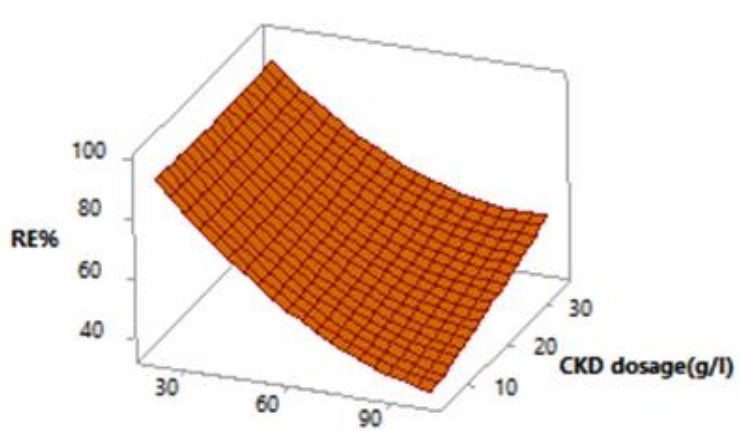

Initial conc. (ppm)

(a)
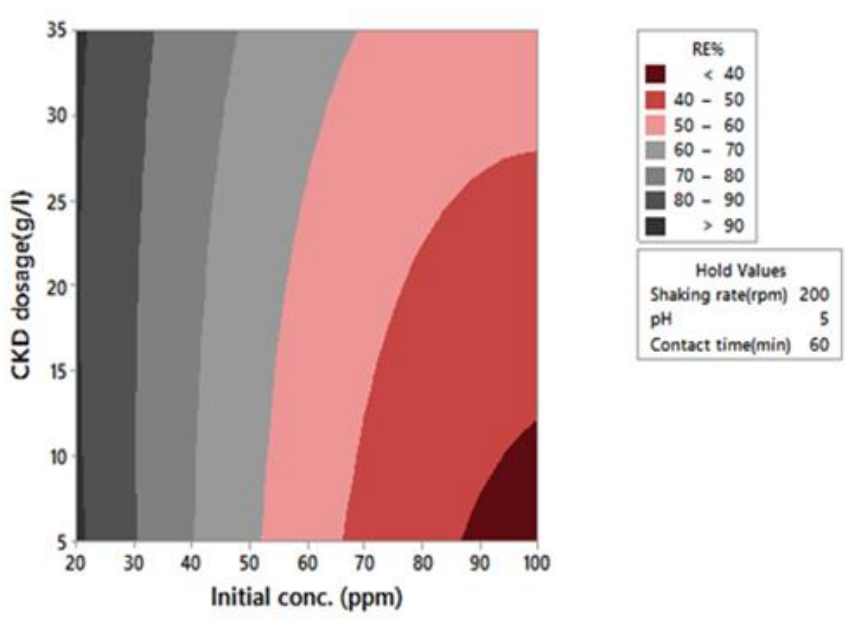

(b)

Figure 5: Response surface plot (a) and contour plot (b) showing the effect of CKD dosage and initial concentration of copper on the copper removal efficiency

\subsection{The optimization and confirmation test}

Numerical optimization of the software is applied to get the precise point that maximized the Desirability Function (DF). The desired goal was chosen by adjusting the weight or importance that could change the characteristics of the aim. Five options for the aim fields for response were selected: maximum, minimum, target, within range, and none. In the present work, the aim is to get higher removal efficiency of Copper so the 'maximum' field with corresponding 'weight' 1.0 was chosen. $35.59 \%$ was taken as the lowest limit for the removal efficiency while $100.00 \%$ was taken as the upper limit. Under these settings and boundaries, the optimization procedure was conducted and the results are displayed in Table 3 with the desirability function of (1). Results of optimization recommended using the initial concentration of copper (20 ppm), shaking rate of (300 rpm), $\mathrm{pH}(8)$, contact time (90 min), and CKD dosage (35 gll) to get higher removal efficiency of $100.6 \%$. 
Two experiments at the optimum values of the process parameters were performed to confirm the results of optimization. $20 \mathrm{ppm}$ was taken as nearly the value of the initial copper concentration resulted from optimization. The results are displayed in Table 4. After $90 \mathrm{~min}, 300 \mathrm{rpm}$, $\mathrm{pH} 8$, and CKD dosage $\mathrm{gll}$ of the experiments, the results are shown in Table 7. A removal efficiency of $100 \%$ acquired, which is within the zone of the expected optimum value of removal efficiency that was acquire from optimization analysis using desirability functions Table 6.

Table 6. Optimum of process parameters for maximum removal efficiency of copper.

\begin{tabular}{cccccccc}
\hline Response & Goal & Lower & Target & Upper & Weight & Importance \\
\hline RE\% & Maximum & 35.59 & 100 & 100 & 1 & 1 \\
\hline Response & Fit & SE Fit & 95\% CI & 95\% PI \\
\hline RE\% & 119.82 & 9.14 & $(101.00 ; 138.64)$ & $(98.36 ; 141.27)$ \\
\hline \multicolumn{7}{c}{ Solution } \\
\hline $\begin{array}{c}\text { Initial } \\
\text { Optimum }\end{array}$ & $\begin{array}{c}\text { Conc. } \\
\text { CKD Shaking }\end{array}$ & $\begin{array}{c}\text { Contact } \\
\text { dosage } \\
\text { parameters }\end{array}$ & $\begin{array}{c}\text { rate } \\
\text { (g/l) }\end{array}$ & PH & $\begin{array}{c}\text { time } \\
\text { (rpm) }\end{array}$ & $\begin{array}{c}\text { RE\% } \\
\text { (min) }\end{array}$ & $\begin{array}{c}\text { Composite } \\
\text { desirability }\end{array}$ \\
\hline RE\% & 20 & 35 & 300 & 8 & 90 & 119.819 & 1 \\
\hline
\end{tabular}

Table 7. Confirmation of the optimum conditions for copper removal efficiency

\begin{tabular}{lccccccc}
\hline RUN & $\begin{array}{c}\text { Initial } \\
\text { conc. } \\
(\mathbf{p p m})\end{array}$ & $\begin{array}{c}\text { CKD } \\
\text { dosage } \\
(\mathbf{g} / \mathbf{l})\end{array}$ & $\begin{array}{c}\text { Shaking } \\
\text { rate } \\
(\mathbf{r p m})\end{array}$ & PH & $\begin{array}{c}\text { Contact } \\
\text { time } \\
(\mathbf{m i n})\end{array}$ & \multicolumn{2}{c}{ RE\% } \\
Actual Average \\
\hline RUN 1 & 20 & 35 & 300 & 8 & 90 & 99.78 & 99.79 \\
RUN 2 & 20 & 35 & 300 & 8 & 90 & 99.80 & 99.79 \\
\hline
\end{tabular}

\section{Conclusions}

It has been demonstrated that the removal of copper from a simulated solution of wastewater can be successfully performed using CKD as an absorbent material. The RMS methodology is applied effectively to improve process parameters and to know the optimum levels of these parameters for copper removal resulting in increased removal efficiency. ANOVA analysis showed a high value of $\mathrm{R}^{2}(0.951)$ as a correlation coefficient indicating good compatibility between the quadratic model and experimental results. Based on RSM analysis, it can be concluded that copper concentration has the greatest influence on the efficiency of copper removal compared to other factors. The optimum values obtained from the improvement were a preliminary $\mathrm{Cu}$ (II) concentration of $20 \mathrm{ppm}, \mathrm{pH} 8$, a shaking rate $300 \mathrm{rpm}$, a 90-minute contact time, and a CKD dose of $35 \mathrm{~g} /$ 1. Under these conditions, it may be possible to reduce the concentration of $\mathrm{Cu}$ (II) from $20 \mathrm{ppm}$ to less than $0.04 \mathrm{ppm}(\mathrm{RE}=99.8 \%)$ at a time of 90 minutes.

\section{Acknowledgments}

The authors appreciate the helpful and technical assistance provided by the staff and technicians in the Chemical Engineering Department, College of Engineering- University of Al-Qadisiyah.

\section{REFERENCES}

[1] M. El Zayat, S. Elagroudy, S. El Haggar, Equilibrium analysis for heavy metal cation removal using cement kiln dust, Water science and technology,
70(6) (2014) 1011-1018.

[2] M. El Zayat, S. Elagroudy, S. El Haggar, Removal of some heavy metals in selected wastewater using cement kiln dust, in: World Environmental and Water Resources Congress 2015, 2015, pp. 2459-2469.

[3] WHO, Copper in Drinking-Water: Background Document for Development of WHO Guidelines for Drinking-Water Quality, in, World Health Organization Geneva, 2004.

[4] A.H. Abbar, Electrochemical removal of copper from a simulated wastewater using a rotating tubular packed bed of woven screens electrode, AlQadisiyah Journal for Engineering Sciences, 12(2) (2019) 127-134.

[5] S.E. Bailey, T.J. Olin, R.M. Bricka, D.D. Adrian, A review of potentially low-cost sorbents for heavy metals, Water research, 33(11) (1999) 24692479.

[6] D. Sud, G. Mahajan, M. Kaur, Agricultural waste material as potential adsorbent for sequestering heavy metal ions from aqueous solutions-A review, Bioresource technology, 99(14) (2008) 6017-6027.

[7] A. Demirbas, Heavy metal adsorption onto agro-based waste materials: a review, J. Hazard. Mater., 157(2-3) (2008) 220-229.

[8] M. Chiban, M. Zerbet, G. Carja, F. Sinan, Application of low-cost adsorbents for arsenic removal: A review, Journal of Environmental Chemistry and Ecotoxicology, 4(5) (2012) 91-102.

[9] P.N. Dave, N. Pandey, H. Thomas, Adsorption of Cr (VI) from aqueous solutions on tea waste and coconut husk, (2012).

[10] Y.A. Mustafa, M.A.A.A. Shaban, Treatment of Wastewater by Cement Kiln Dust, Association of Arab Universities Journal of Engineering Sciences, 24(2) (2017) 31-46.

[11] M. Rahman, S. Rehman, O. Al-Amoudi, Literature review on cement kiln dust usage in soil and waste stabilization and experimental investigation, International Journal of Research and Reviews in Applied Sciences, 7(1) (2011) 77-87.

[12] A.L. Mackie, M.E. Walsh, Bench-scale study of active mine water treatment using cement kiln dust (CKD) as a neutralization agent, Water research, 46(2) (2012) 327-334.

[13] M.G. Klimantavièiûtë, D. Virbalytë, V. Pakðtas, R. Juðkënas, A. Pigaga, Interaction of heavy metal ions with cement kiln dust, Ekologija, 1 (2005) 31-36.

[14] S. Coruh, S. Elevli, Optimization study of dye removal by cement kiln dust using the central composite design of experiments, Global NEST Journal, 17(1) (2015) 93-102.

[15] A.E.-E.A.Z. Amin, S.A. Selmy, Effect of $\mathrm{pH}$ on removal of $\mathrm{Cu}, \mathrm{Cd}, \mathrm{Zn}$, and $\mathrm{Ni}$ by cement kiln dust in aqueous solution, Communications in Soil Science and Plant Analysis, 48(11) (2017) 1301-1308.

[16] M.A. Bezerra, R.E. Santelli, E.P. Oliveira, L.S. Villar, L.A. Escaleira, Response surface methodology (RSM) as a tool for optimization in analytical chemistry, Talanta, 76(5) (2008) 965-977.

[17] M. Evans, Optimisation of manufacturing processes: a response surface approach, Maney Pub, 2003.

[18] L. Huiping, Z. Guoqun, N. Shanting, L. Yiguo, Technologic parameter optimization of gas quenching process using response surface method, Computational Materials Science, 38(4) (2007) 561-570.

[19] A.H. Abbar, Removal of Cadmium from Simulated Wastewater using Rotating Tubular Packed Bed Electrochemical Reactor: Optimization through Response Surface Methodology, Al-Qadisiyah Journal for Engineering Sciences, 13(2) (2020) 91-98.

[20] A.H. Abbar, R.H. Salman, A.S. Abbas, Cadmium removal using a spiralwound woven wire meshes packed bed rotating cylinder electrode, Environmental Technology \& Innovation, 13 (2019) 233-243.

[21] J. Segurola, N.S. Allen, M. Edge, A. Mc Mahon, Design of eutectic photoinitiator blends for UV/visible curable acrylated printing inks and coatings, Progress in Organic Coatings, 37(1-2) (1999) 23-37.

[22] M. El-Awady, T. Sami, Removal of heavy metals by cement kiln dust, Bul . Environ. Contam. Toxicol., 59(4) (1997) 603-610. 